University of Montana

ScholarWorks at University of Montana

$7-2006$

\title{
Stress Responses in Tropical Sparrows: Comparing Tropical and Temperate Zonotrichia
}

Haruka Wada

Ignacio T. Moore

Creagh W. Breuner

University of Montana - Missoula, creagh.breuner@umontana.edu

John C. Wingfield

Follow this and additional works at: https://scholarworks.umt.edu/biosci_pubs

Part of the Biology Commons

Let us know how access to this document benefits you.

\section{Recommended Citation}

Wada, Haruka; Moore, Ignacio T.; Breuner, Creagh W.; and Wingfield, John C., "Stress Responses in Tropical Sparrows: Comparing Tropical and Temperate Zonotrichia" (2006). Biological Sciences Faculty Publications. 71.

https://scholarworks.umt.edu/biosci_pubs/71

This Article is brought to you for free and open access by the Biological Sciences at ScholarWorks at University of Montana. It has been accepted for inclusion in Biological Sciences Faculty Publications by an authorized administrator of ScholarWorks at University of Montana. For more information, please contact scholarworks@mso.umt.edu. 


\section{Stress Responses in Tropical Sparrows: Comparing Tropical and Temperate Zonotrichia}

\author{
Haruka Wada ${ }^{1, *}$ \\ Ignacio T. Moore ${ }^{2, \dagger}$ \\ Creagh W. Breuner ${ }^{3, \neq}$ \\ John C. Wingfield ${ }^{4, \S}$ \\ ${ }^{1}$ Integrative Biology, 1 University Station, University of Texas, \\ Austin, Texas 78712; ${ }^{2}$ Department of Biology, Virginia \\ Polytechnic Institute and State University, Blacksburg, \\ Virginia 24061-0406; ${ }^{3}$ Division of Biological Sciences, \\ Organismal Biology and Ecology, University of Montana, \\ Missoula, Montana 59812; ${ }^{4}$ Department of Biology, \\ University of Washington, Seattle, Washington 98195
}

Accepted 12/8/2005; Electronically Published 6/19/2006

\begin{abstract}
Seasonal modulation of the adrenocortical response appears to be ubiquitous in mid- to high-latitude vertebrates but has not been investigated in tropical vertebrates. Previous studies demonstrate that temperate passerines show seasonality in corticosterone secretion and corticosteroid binding globulin capacities. We examined seasonal and sex differences in the stress response in an equatorial population of Zonotrichia capensis, the only Zonotrichia that breeds in the tropics, and compared the results with those of northern Zonotrichia. Seasonal differences in tropical Zonotrichia would presumably be independent of photoperiod and thus directly related to such activities as reproduction and feather molt. In addition, we investigated the possible role of binding globulin as a sex steroid binding globulin, as suggested for temperate passerines. Similar to northern congeners, $Z$. capensis show seasonal modulation in total corticosterone and binding globulin capacity with higher levels during breeding than molt. However, unlike many temperate passerines, there are no sex differences in corticosterone secretion or binding globulin capacity. Furthermore, the seasonal differences in total corticosterone diminish when the free levels are calculated. The contrast between equatorial and northern congeners indicates factors such as breeding environment and
\end{abstract}

\footnotetext{
*Corresponding author; e-mail: haruka@mail.utexas.edu.

${ }^{\dagger}$ E-mail: itmoore@vt.edu.

${ }^{\ddagger}$ E-mail: creagh@mail.utexas.edu.

${ }^{\S}$ E-mail: jwingfie@u.washington.edu.
}

Physiological and Biochemical Zoology 79(4):784-792. 2006. (C) 2006 by The University of Chicago. All rights reserved. 1522-2152/2006/7904-4174\$15.00 life-history strategy may play important roles in shaping stress response in these species.

\section{Introduction}

Many vertebrates cope with a stressor, and thereby increase their chances of survival, by activating the hypothalamicpituitary-adrenal (HPA) axis. Glucocorticoids from the adrenal glands shunt energy to vital organs, suppress nonessential behaviors, and promote escape behaviors (Sapolsky 1992; Sapolsky et al. 2000; Wingfield and Romero 2000; Wingfield and Kitaysky 2002; Wingfield and Sapolsky 2003). However, persistent stress can inhibit reproduction, suppress the immune system and growth, and promote protein loss, leading to lower fitness for the individual (Sapolsky et al. 2000). Similarly, hypersensitivity to a stressor while rearing young can also lower an individual's fitness, as high glucocorticoid levels can lead to the abandonment of a nest or young. Thus, it is important for an animal to tightly regulate the reactivity of the HPA axis according to its life-history status. This regulation can be achieved at multiple levels. Here we discuss two levels: the modulation of sensitivity to a stressor through altering reactivity of the HPA axis and the modulation of bioavailability of the hormone to tissues once in the plasma.

In the blood, steroid hormones can be either bound to a binding globulin or free (unbound). According to the free hormone hypothesis, only free hormone can enter tissues or be broken down, and therefore it is the biologically active form (Ekins 1990; Breuner and Orchinik 2002). Consequently, animals can alter free hormone levels without any changes in secretion rate by changing binding globulin capacities (the total number of binding sites present). Corticosteroid binding globulin (CBG) in birds is one of these globulins: glucocorticoids bind to CBG with high affinity, and testosterone binds with lower affinity (Silverin 1986; Deviche et al. 2001). Food shortage, for example, is known to reduce CBG levels in whitecrowned sparrows (Zonotrichia leucophrys gambelii: Lynn et al. 2003a). Although this change in CBG did not take place until after $22 \mathrm{~h}$, it extended the period of higher free glucocorticoid levels even after corticosterone secretion had subsided. This suggests that animals can reduce CBG levels, dissociating corticosterone to sustain high levels of free hormone during such an event. Another study in house sparrows (Passer domesticus: Breuner and Orchinik 2001) supports a reservoir-like function 
of CBG. Total (bound and unbound) levels and CBG capacities showed very similar seasonal changes in this species. Although the resultant free levels showed no seasonal changes, CBGbound corticosterone reservoir doubled during the nesting period.

In birds, researchers have suggested another function of CBG: a sex steroid binding globulin. Unlike mammals, birds lack apparent sex steroid specific binding globulins in the blood (Deviche et al. 2001; Breuner and Orchinik 2002). However, several studies demonstrate that CBG binds to androgens, although affinity of testosterone to $\mathrm{CBG}$ is lower than that of glucocorticoids. These studies suggest CBG as a physiologically relevant binding globulin for testosterone in temperate-zone male passerines. Further evidence comes from two other lines of sources. First, studies demonstrate a positive relationship between testosterone and CBG levels. Males often have higher testosterone and CBG levels than females during the breeding season (pied flycatchers: Silverin 1986; white-crowned sparrows: Romero and Wingfield 1998; dark-eyed juncos: Deviche et al. 2001) and higher during breeding compared with the nonbreeding season (house sparrows: Breuner and Orchinik 2001). Second, testosterone implants increase CBG capacity in dark-eyed juncos, suggesting a direct relationship between the two factors (Klukowski et al. 1997). However, testosterone implants also increased endogenous corticosterone secretion, so it is not clear which hormone is responsible for the increase in CBG.

Similar to CBG levels, glucocorticoid secretion also shows seasonal modulations and sex differences across vertebrate taxa (see Romero 2002 for review). Gambel's white-crowned sparrows (Z. l. gambelii), for example, breed in the Arctic, and their adrenocortical response to handling stress is greatest during breeding, lowest during molt, and moderate during the nonbreeding season (Astheimer et al. 1994). This suggests that these birds increase the sensitivity of the HPA axis during the breeding season. Romero and Wingfield (1998) further showed that this seasonal change in sensitivity is caused by changes in adrenal reactivity to pituitary adrenocorticotropic hormone. This difference, greater glucocorticoid secretion during breeding, is different from some birds that actually suppress the stress response during breeding (Romero 2002). Sex differences in glucocorticoid secretion, on the other hand, appear to be more complex. Stages within the breeding season and degree of parental care both appear to have significant roles in determining these sex differences (Romero et al. 1997; O'Reilly and Wingfield 2001; Holberton and Wingfield 2003; Lynn et al. 2003b). This is especially the case for species with limited time and energy to breed. For instance, in a territorial, monogamous, and biparental species such as $Z$. l. gambelii, reproductive investment of a female is expected to be higher during the preparental stage than for a male. However, as chicks hatch and both parents provision them, the sex difference in reproductive effort is expected to cease (Holberton and Wingfield 2003).
Similarly, Z. l. gambelii shows a sex difference in adrenocortical response during preparental stage (Astheimer et al. 1994; Holberton and Wingfield 2003), while no sex differences during parental stage (Holberton and Wingfield 2003).

Different breeding environments can lead to differences in sensitivity and the regulation of the HPA axis. Comparisons among closely related species provide a powerful tool in investigating the effects of different environments on the stress response. Depending on the latitude and migratory pattern, those closely related species can differ in length of breeding season and thus costs of reproduction, food availability, and predictability and severity of weather. Species in the genus $\mathrm{Zo}$ notrichia provide a good model as they vary in breeding latitudes ranging from the Arctic to the equator. Previously, temperate breeding Zonotrichia species were used for such comparisons (Breuner et al. 2003). In this study, we extend the investigation to Zonotrichia capensis, the only Zonotrichia species that breeds in the tropics (in the case of this study, at the equator). This species ranges from southern Mexico to southern Argentina and from sea level up to $4,000 \mathrm{~m}$ elevation in some areas. Our study population is ideal for such a comparison since it shows strong reproductive seasonality, similar to its northern congeners; however, this seasonality is associated with environmental cues other than photoperiod (Moore et al. $2004 b$, 2005). Furthermore, our population is nonmigratory and has an equivalent or a longer breeding season than its congeners in the temperate zones.

In this study, we examined seasonal and sex differences in baseline and stress-induced corticosterone levels in equatorial Zonotrichia capensis using a standardized capture and handling protocol (Wingfield 1994). In addition, we examined the seasonal modulation of $\mathrm{CBG}$ capacity and thus the seasonal changes in regulation of corticosterone bioavailability to the tissues. Previous studies show that some tropical birds have extremely low levels of testosterone during the breeding season (Wikelski et al. 1999; Hau et al. 2000). In contrast, our population of $Z$. capensis has comparable or higher levels of testosterone than its northern sister species (Moore et al. 2002; Goymann et al. 2004). Thus, we hypothesized that similar to northern species, corticosterone levels and CBG capacity of this species are higher during breeding season than during molt and higher in males than in females. We also predicted that the seasonal modulations in the HPA axis are smaller than those of northern congeners because the season-to-season changes in climate and food availability are less pronounced in the tropics. To our knowledge, this is the first study to investigate adrenocortical reactivity and modulation in a tropical bird.

\section{Material and Methods}

\section{Study Animals}

The rufous-collared sparrow Zonotrichia capensis is a polytypic species (King 1973, 1974) composed of over 20 subspecies 
(Chapman 1940). It ranges from southern Mexico to southern Argentina and Chile, and populations vary in habitat, number of molts per year (Kalma 1970), and migratory pattern. The birds in this study are from a sedentary population in Papallacta, Ecuador ( $0^{\circ} 21^{\prime} \mathrm{S}, 3,300 \mathrm{~m}$ elevation). Due to the close proximity to the equator, there is only $\sim 3$ min difference in day length throughout the year (Moore et al. 2004a). However, there is a seasonal pattern in other climatic variables, primarily rainfall (Bendix and Rafiqpoor 2001; Moore et al. 2005). Previous studies have demonstrated that breeding is independent of photoperiod in this population (Moore et al. $2004 b$, 2005). Although this species has been observed to have a year-round breeding in some areas (Miller and Miller 1968), this population exhibits a clear breeding season from September to December and a synchronized prebasic molt during January and February (I. T. Moore, unpublished observations). It is interesting to note that occasionally this population can breed outside of the normal breeding season, as suggested by a report of breeding occurring in May during an El Niño year (J. C. Wingfield and I. T. Moore, unpublished observations). In addition, these birds are socially monogamous, with males contributing to parental care (Miller and Miller 1968).

\section{Stress Protocol}

Birds were caught through passive netting or by using prerecorded song playback to attract them into the net. Upon capture, birds were subjected to a standardized stress protocol: the initial blood samples (baseline) were collected within $4 \mathrm{~min}$, with a second sample taken after $30 \mathrm{~min}$ restraint in a cloth bag. Corticosterone levels in the blood of birds normally do not become elevated until 3 min after capture (Wingfield et al. 1982); however, in our study, corticosterone levels obtained between 2 and $3 \mathrm{~min}$ and between 3 and $4 \mathrm{~min}$ were not significantly different from each other (ANOVA; $P=0.7946$ ). Therefore, to increase our sample size for further analyses, we considered the data collected before $4 \mathrm{~min}$ to represent baseline levels. For blood sampling, 20-30 $\mu$ L blood were collected from the alar vein into heparinized microhematocrit capillary tubes. The samples were kept cold on ice until the end of the day. The blood was then centrifuged to separate the plasma, which was kept frozen until the assay.

Samples for three stages (early breeding, middle breeding, and molting) were collected September 1-25, 2002, October 16-22, 2003, and February 3-27, 2001 respectively. For females, average brood patch scores were $1.2 \pm 0.7$ (early breeding), $2.1 \pm 0.3$ (middle breeding) and 0 (molt), where 3 represents fully defeathered and edematized brood patch. For males, average cloacal protuberance lengths were $4.3 \pm 0.7 \mathrm{~mm}$ (early breeding), $6.4 \pm 0.3 \mathrm{~mm}$ (middle breeding), and $1.9 \pm 0.3 \mathrm{~mm}$ (molt). Cloacal protuberance length closely tracks testis volume. All the individuals were banded on capture. For seven out of 53 individuals, stress series samples were collected at two dif- ferent reproductive stages. Although this is not ideal, the samples were treated statically as independent because they were obtained in different years and at different times of the year.

\section{Sample Processing and Assays}

Plasma corticosterone was analyzed by either direct radioimmunoassay or following chromatographic separation (Wingfield et al. 1992). The average recoveries after extraction were $83 \%$. The limit of detection for the assay was $\sim 2 \mathrm{ng} / \mathrm{mL}$, depending on plasma volume used. The samples were run in four assays with intra-assay and interassay variations of $5.4 \%$ and $19.6 \%$, respectively.

Testosterone data were obtained from Moore et al. (2005). Plasma testosterone levels were measured by radioimmunoassay. Steroids were first extracted using distilled dichloromethane followed by chromatographic separation. The limit of detection for the assay was $0.05 \mathrm{ng} / \mathrm{mL}$ and depended on the volume of plasma used in the assay. Average intra-assay variation was $13 \%$.

CBG capacity and affinity were determined in a ligand-binding assay using tritiated corticosterone as described in Breuner et al. (2003). For all assays, total binding was determined using $50 \mu \mathrm{L} 3 \mathrm{H}$ corticosterone, $50 \mu \mathrm{L}$ buffer, and $50 \mu \mathrm{L}$ stripped and diluted plasma. Nonspecific binding was determined using 50 $\mu \mathrm{L} 1 \mu \mathrm{M}$ unlabeled corticosterone instead of buffer. Characterization assays were run first using pooled plasma to determine the optimal plasma dilution, incubation duration, affinity, and specificity of CBG for this species. The dissociation constant $\left(K_{d}\right)$ was determined through equilibrium saturation binding, with $3 \mathrm{H}$ corticosterone ranging from 0.23 to $12 \mathrm{nM}$. The specificity of the binding site for corticosterone was determined by a $3 \mathrm{H}$ corticosterone competition curve experiment. In the experiment, unlabeled corticosterone, testosterone, and estradiol competed for the binding site with labeled corticosterone. Individual samples were run in point-sample analysis using $19 \mathrm{nM} 3 \mathrm{H}$ corticosterone. Based on affinity estimated from equilibrium saturation binding, this ligand concentration should occupy approximately $85 \%$ of the total binding site. We adjusted the CBG capacity to $100 \%$ for free corticosterone analysis. All assays were performed at $4^{\circ} \mathrm{C}$, with an incubation period of $2 \mathrm{~h}$ and final plasma dilution of $1: 900$. It is thought that CBG levels do not change within $1 \mathrm{~h}$ of capture and handling stress in Zonotrichia (Lynn et al. 2003a; Breuner et al., forthcoming), and thus plasma collected either for baseline or stress-induced levels were used for the point-sample analysis. All samples used in the analysis were run in one assay with intra-assay variation of $12.5 \%$.

\section{Statistical Analysis}

The effects of sex and reproductive stage on hormone levels and their interactions for total and free corticosterone levels 


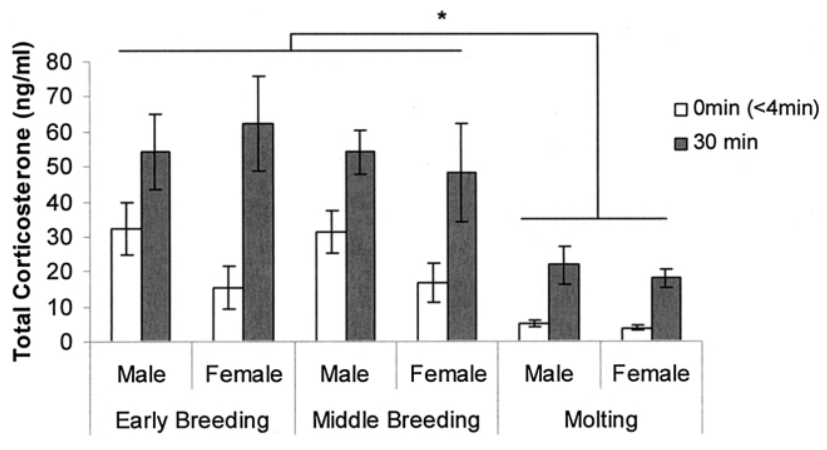

Figure 1. Baseline and stress-induced levels of total corticosterone for stages of breeding and molt in both sexes (means \pm SE, asterisk indicates $P<0.05 ; n=9,5,8,10,8$, and 13, respectively). Overall, birds elevated corticosterone significantly in response to handling stress. Levels during breeding stages were significantly higher than molting.

were determined using two-factor repeated-measures ANOVAs within each stress series followed by Tukey HSD (SPSS 11.5). Where the significant interaction was found, the possible pairwise comparisons were made followed by Bonferroni correction. Differences in CBG capacities between reproductive stages and sexes were determined using factorial ANOVA followed by Tukey HSD. Free corticosterone levels were log transformed to correct for heteroscedasticity before the analysis. Differences in testosterone levels between reproductive stages and sexes were determined using factorial ANOVA followed by Tukey HSD. To determine whether or not there were sex differences during breeding stages, $t$-tests were performed followed by Bonferonni adjustment. Results were considered significant when $\alpha \leq$ 0.05. Data from CBG saturation and competition curves were transformed and curve fitted using GraphPad Prism (San Diego, CA).

Free levels of corticosterone were estimated with the use of the equation in Barsono and Baumann (1989):

$$
\begin{gathered}
H_{\text {free }}=0.5 \\
\times\left[H_{\text {total }}-B_{\max }-\frac{1}{\mathrm{~K}_{\mathrm{a}}} \pm \sqrt{\left(B_{\max }-H_{\text {total }}+\frac{1}{\mathrm{~K}_{\mathrm{a}}}\right)^{2}+4\left(\frac{H_{\text {total }}}{\mathrm{K}_{\mathrm{a}}}\right)}\right]
\end{gathered}
$$

where $K_{a}$ is $1 / K_{d}(n M), K_{d}$ is affinity of corticosterone for CBG, $B_{\max }$ is total CBG capacity, and $H_{\text {total }}$ is total plasma hormone concentration.

In four out of 54 samples, total hormone levels exceeded CBG capacity. This discrepancy leads to greatly elevated free corticosterone estimations, which fall outside two standard deviations of the mean. Accordingly, these samples were removed from the analysis. For reasons we do not know, three of the females during early breeding stage fall in this category, decreasing the sample size. Therefore, free corticosterone levels for females during early breeding stage were excluded from further analysis. In addition, two individuals had either total corticosterone level or CBG level that fell outside of two standard deviations of the mean and were thus removed from the analysis.

\section{Results}

Total Corticosterone Levels

Overall, handling stress had a significant effect on corticosterone levels (Fig. $1 ; F_{1,51}=55.58, P<0.0001$ ). Reproductive stage also had a significant effect on hormone level $\left(F_{2,50}=13.35\right.$, $P<0.0001)$. Individuals in the early and middle breeding stages had significantly higher levels compared with molt $(P<0.05)$. There was no significant effect of sex on corticosterone levels $\left(F_{1,51}=1.20, P=0.280\right)$, nor was there significant interaction between sex and reproductive stage $\left(F_{2,50}=0.24, P=0.790\right)$.

\section{Corticosterone Binding Globulin}

The equilibrium saturation binding experiment showed a single binding site for corticosterone (Fig. $2 ; \mathrm{K}_{\mathrm{d}}=3.47 \pm 0.17 \mathrm{nM}$ ). Competition analysis demonstrates testosterone has an approximately fivefold-lower affinity than corticosterone, while binding of estradiol is negligible (Fig. 3).

For CBG capacity, there was a significant overall effect of reproductive stage (Fig. $4 ; F_{2,49}=10.52, P=0.0001$ ). Although the effect of sex on CBG levels was not significant, there was a strong trend $\left(F_{1,50}=3.50, P=0.068\right)$. No significant interaction between reproductive stage and sex was found $\left(F_{2,49}=2.02, P=0.144\right)$. Birds had significantly higher capacity of CBG during two breeding stages compared with molt $(P<0.05)$.

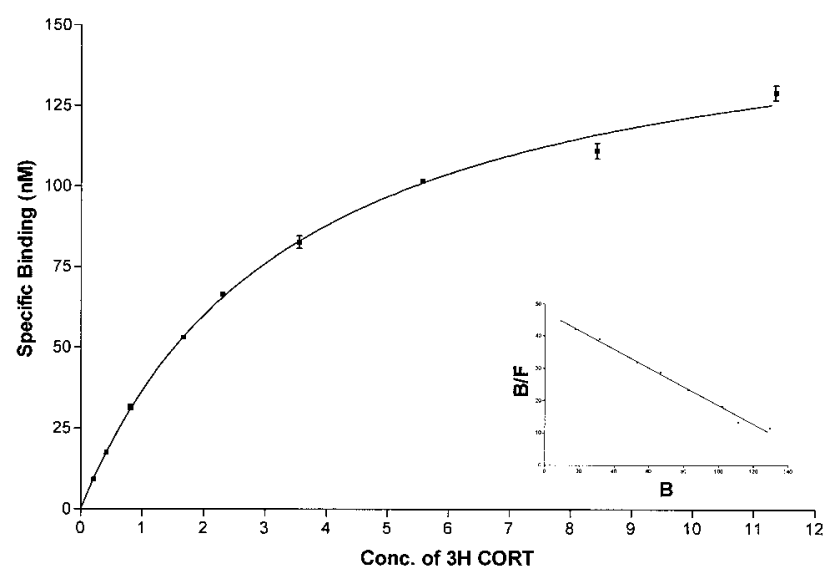

Figure 2. Equilibrium-saturation-binding curve at $4^{\circ} \mathrm{C}$ demonstrating the specific binding of $3 \mathrm{H}$ corticosterone to Zonotrichia capensis plasma. The inlay is a Scatchard-Rosenthal replot of the same data, where $\mathrm{B}$ represents specific binding and $\mathrm{F}$ represents free $3 \mathrm{H}$ corticosterone concentration. Data were best fit by a one-site-binding model with $\mathrm{K}_{\mathrm{d}}=3.47 \pm 0.17 \mathrm{nM}$. 


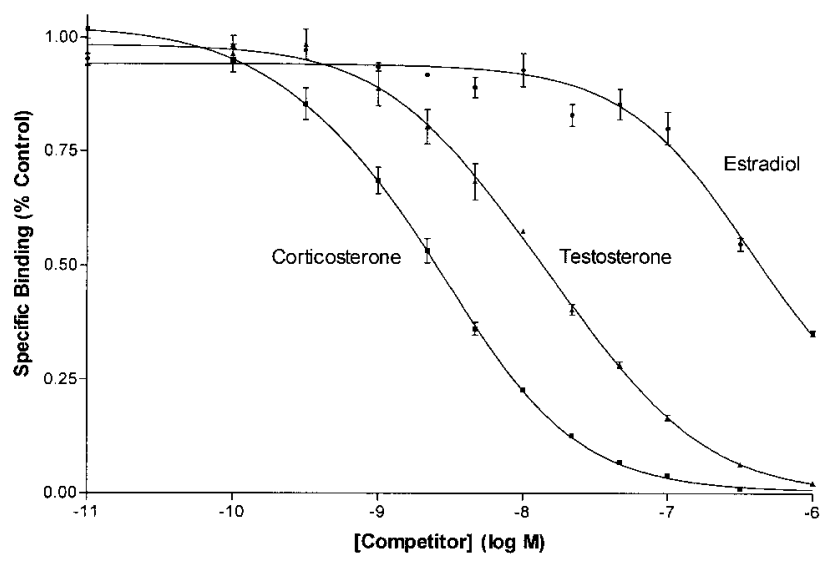

Figure 3. Competition curves demonstrating the specific binding of $3 \mathrm{H}$ corticosterone to increasing concentrations of unlabeled hormones in Zonotrichia capensis plasma. $\mathrm{K}_{i}$, where the concentration of cold competitor required to bind $50 \%$ of $3 \mathrm{H}$ hormone, for corticosterone, testosterone, and estradiol are $2.49 \pm 0.16 \mathrm{nM}, 13.53 \pm 1.28 \mathrm{nM}$, and $0.36 \pm 0.098 \mu \mathrm{M}$, respectively.

\section{Free Corticosterone Levels}

Repeated-measures ANOVA analysis for middle breeding and molt showed there was no stage difference in free hormone levels (Fig. $5 ; F_{1,36}=2.22, P=0.145$ ). On the other hand, there was an overall sex difference $\left(F_{1,36}=6.43, P=0.016\right)$. There was also a significant interaction between sex and reproductive stage $\left(F_{1,36}=5.43, P=0.026\right)$. Pairwise comparison results indicated that while there was no sex difference during molt and in stress-induced levels during middle breeding, males had significantly higher baseline levels than females during middle breeding $(P \leq 0.05)$. Overall, birds elevated free corticosterone levels in response to handling stress $\left(F_{1,36}=74.46, P<0.0001\right)$.

\section{Relationship between Testosterone and CBG}

Overall, there was a significant effect of sex on testosterone levels across both breeding stages, with males having higher levels than females (Fig. 6; $F_{1,33}=8.45, P=0.007$ ). On the other hand, there was no overall effect of reproductive stage on testosterone levels $\left(F_{1,33}=1.41, P=0.244\right)$ or interaction between sex and reproductive stage $\left(F_{1,33}=1.56, P=0.221\right)$. When comparisons between sexes were made for each stage, the sex difference was significant only during the middle breeding stage $(P<0.05)$. A scatter plot of the correlation between testosterone and CBG levels showed there was no significant correlation between the two $\left(R^{2}=0.0061\right)$.

\section{Discussion}

Similar to northern congeners, Zonotrichia capensis show seasonal modulation in total corticosterone and CBG capacity. Both total hormone and CBG levels are significantly higher during breeding than during molt for both sexes. Interestingly, however, there is a striking difference between $Z$. capensis and Gamble's white-crowned sparrow (Zonotrichia leucophrys gambelii) in adrenocortical reactivity: $Z$. capensis do not show the upregulation of stress response at the earlier breeding stage, while $Z$. l. gambelii exhibit robust response. Unlike many temperate zone passerines, there are no sex differences in corticosterone secretion or CBG capacity. Due to the same directional changes in CBG with total hormone, all of the seasonal differences in total hormone diminish when the free corticosterone levels are calculated. This is similar to house sparrows (Passer domesticus) in temperate zones (Breuner and Orchinik 2001).

Many vertebrates exhibit seasonal changes and sex differences in sensitivity and regulation of the HPA axis. Studies have demonstrated that captive birds show less seasonal modulation in reactivity of the HPA axis compared with free-living animals (e.g., Romero and Wingfield 1999). This suggests that environment plays an important role in modulating reactivity of the HPA axis seasonally. Photoperiod, temperature, and food availability are suspected for those seasonal modulations; however, the exact cause is still unknown (Romero 2002). From this study, it appears that photoperiod alone is not the driver of seasonal plasticity of the stress response, as our study population resides on the equator, where photoperiod cues are minimal. In this section, we will discuss the environment, migratory pattern, and social roles as factors shaping stress response in $Z$. capensis as we draw contrasts between $Z$. capensis and its sister species, especially the well-studied Z. leucophrys.

\section{Seasonality in the Environment and Migratory Pattern}

Breeding environments and life-history strategies, such as migratory patterns, can exert evolutionary pressure and shape the

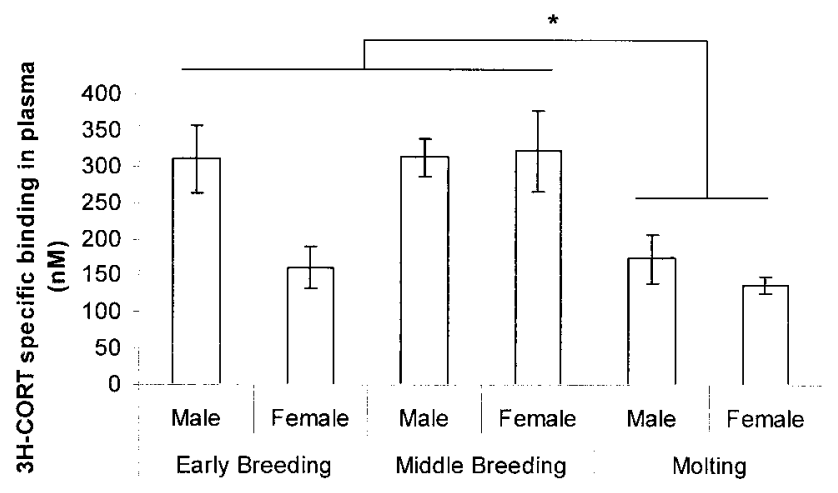

Figure 4. Changes in specific binding of corticosterone to CBG across stages for each sex (mean $\pm \mathrm{SE}$, asterisk indicates $P<0.05 ; n=8,5$, $8,10,8$, and 13, respectively). Stages had a significant effect on CBG levels, while there was no effect by sex. In addition, there was no interaction between sex and stages. Overall, birds had significantly higher CBG levels during early and middle breeding compared with molt. 


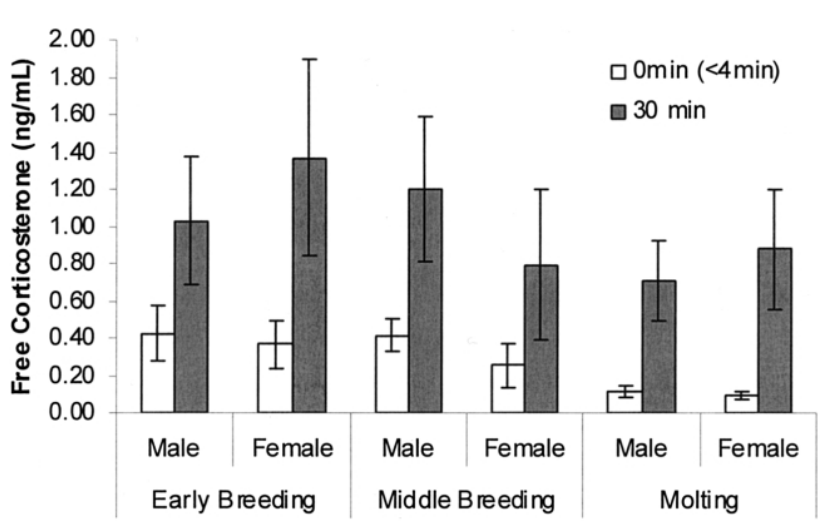

Figure 5. Estimated free corticosterone levels for each sex during stages of breeding and molt (mean $\pm \mathrm{SE} ; n=8,2,8,9,8$, and 13, respectively). Due to the small sample size, females of the early breeding stage were excluded from statistical analysis. There was significant effect of sex but no effect of stage on free corticosterone levels during the later two stages.

stress response (Romero 2002). Depending on their natural history, populations differ in length of breeding season, severity and unpredictability of weather, food availability, and thus cost of reproduction (Breuner et al. 2003) and molt. These differences can lead to variations in sensitivity of the HPA axis and how tightly the availability of the hormone to the tissue is regulated. In contrast to temperate zones, the equatorial population of $Z$. capensis experiences minimal seasonal changes in photoperiod; however, rainfall does show a seasonal pattern (Bendix and Rafiqpoor 2001; Moore et al. 2005). The 4-mo breeding season in this population is much longer than that of some closely related species, namely, Z. l. gambelii (e.g., Holberton and Wingfield 2003) and Zonotrichia leucophrys oriantha (Morton 2002), but comparable to Zonotrichia leucophrys pugetensis and Zonotrichia leucophrys nuttalii. Unlike $Z$. l. gambelii and Z. l. oriantha, birds in our population are nonmigratory; however, they aggressively defend their territories only during the breeding season (Moore et al. 2004a).

Birds in our population have similar general patterns of seasonal changes in CBG capacities and total corticosterone compared with temperate passerines. Levels are higher during breeding season than during molt. Although snow buntings (Plectrophenax nivalis) have no such changes between the two seasons (Romero et al. 1998a), most others, such as pied flycatchers (Ficedula hypoleuca: Silverin 1986), house sparrows (Passer domesticus: Breuner and Orchinik 2001), white-crowned sparrows (Z. leucophrys: Romero and Wingfield 1998), and Lapland longspurs (Romero et al. 1998b), have higher levels of CBG early in the breeding season as compared with late breeding or molt. Similarly, northern passerines have higher sensitivity to stress during nesting compared with nonbreeding $(Z$. l. gambelii: Astheimer et al. 1994; Holberton and Wingfield 2003; house sparrows: Breuner and Orchinik 2001). In northern temperate zones, seasonality in photoperiod drives reproductive cycles directly, which are then fine-tuned through changes in such factors as food availability and temperature. In contrast, our equatorial population experiences little change in photoperiod. However, there are seasonal changes in other climatic variables, such as rainfall, that may drive the reproductive cycle. These changes in rainfall may influence other physiological parameters, such as HPA axis reactivity and CBG levels. It is also possible that an endogenous rhythm drives the seasonality (Gwinner and Dittami 1990). It is interesting to note that although this general pattern is similar between $Z$. capensis and northern passerines, males of $Z$. capensis lack the upregulation of adrenocortical response during prenesting. Although it may be due to the relatively small sample size, it is also possible that further modulation within a breeding season is determined by other factors such as social cues or other cues in the environment.

While total corticosterone and CBG capacities show distinct seasonal changes, there is no seasonal change in free corticosterone levels. This same pattern is seen in the temperate house sparrow (Breuner and Orchinik 2001) and appears to occur in several other arctic and temperate species (Romero and Wingfield 1998). If free hormone is the biologically active fraction (Breuner and Orchinik 2002), then why would animals regulate total corticosterone in such a robust manner? There are two possibilities. On the one hand, total corticosterone may be the more relevant fraction in that CBG may not limit access of hormone to tissues. On the other hand, with greater CBGbound corticosterone during breeding, it may be that a greater plasma reservoir of corticosterone is needed during breeding. CBG has the interesting property of being cleaved by activated neutrophils (Pemberton et al. 1988). Therefore, at sites of inflammation, CBG will be cleaved to release corticosterone directly at the site where it may modulate immune activity. Acute corticosterone increase has been associated with entry of im-

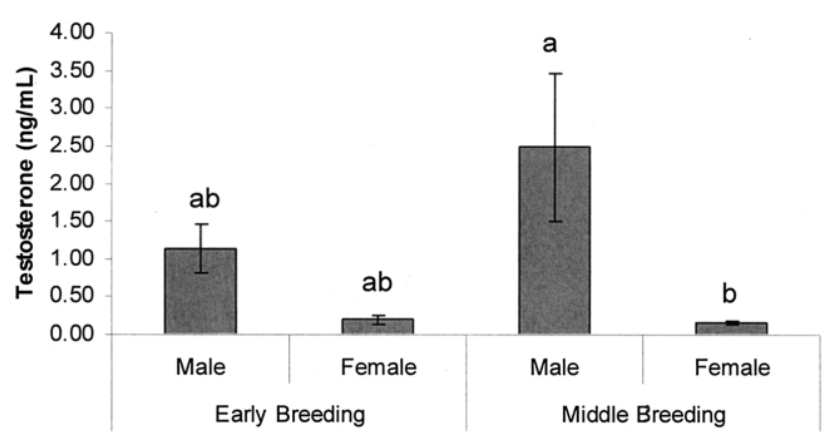

Figure 6. Testosterone levels of both sexes during early and middle breeding stages (mean \pm SE; $n=9,5,9$, and 12 , respectively). Overall, males had significantly higher testosterone levels than females. The $t$ test results showed that the significant sex difference was found only during middle breeding. The data were obtained from Moore et al. (2005). 
mune cells into tissue (therefore enhancing immune activity) over short time frames. Therefore, greater corticosterone reservoir during breeding may allow for a rapid upregulation of immune function at sites of inflammation without further increase in total corticosterone secretion.

Glucocorticoids play an important role in energy mobilization; however, they suppress growth (see Sapolsky et al. 2000 for review), possibly feather growth, after chronic stress. In fact, Z. l. gambelii reportedly has a severely reduced response during prebasic, or postnuptial, molt (Astheimer et al. 1994). In contrast, $Z$. capensis undergoing prebasic molt shows a significant increase in corticosterone after $30 \mathrm{~min}$ of capture, although it is below levels during breeding. These opposing results may be explained by the differences in the duration of molt between the two species. Zonotrichia leucophrys gambelii molts in around 5 wk (Wingfield and Farner 1993), while Z. capensis takes a minimum of 2 mo to complete molt (in a Columbian population: Miller 1961). This raises the possibility that molt in $Z$. capensis may not be as acutely energetically costly as in temperate Zonotrichia species because it occurs over a longer period of time. This may allow less evolutionary pressure on suppressing corticosterone secretion in $Z$. capensis compared with northern congeners. Several populations of $Z$. capensis are reported to have full testis or full cloacal protuberance size during various molt stages (Miller 1961; Wolf 1969; Kalma 1970; King 1974), which further suggests that molt is not as energetically costly in these populations (although in our population, the males regress their testes during molt). Further investigation is needed to test the relationship between energetic cost of molt and the degree of seasonal change in adrenal and pituitary sensitivity with these populations.

These results suggest that environmental factors other than photoperiod and cost of molting have important roles in shaping stress response. Furthermore, studies in the equatorial population imply that changes in the environment can affect the HPA axis in the absence of photoperiodic or temperature changes. Here, the seasonal modulations in the HPA axis and CBG levels are associated with changes in reproductive activity.

\section{Social Roles: Parental Care}

Social roles, such as status (Wingfield et al. 1991) and degree of parental care (Wingfield et al. 1995; O'Reilly and Wingfield 2001; Holberton and Wingfield 2003; Lynn et al. 2003b), can also have an effect on adrenocortical response. It has been hypothesized that a sexual dimorphism in stress response during nesting is due to differential involvement in parental care in species with extreme time constraint on breeding (Arctic birds: Wingfield et al. 1995; O'Reilly and Wingfield 2001; Holberton and Wingfield 2003). This hypothesis states that when animals have fewer opportunities to renest, the sex providing more parental care should have lower stress response than the other sex. Studies have shown that when the time investment between the sexes is similar during nesting phase (chestnutcollared and McCown's longspurs, Calcarius ornatus and Calcarius mccownii: Lynn et al. 2003b) and parental phase (O'Reilly and Wingfield 2001; Holberton and Wingfield 2003; Lynn et al. 2003b), there is no sex difference between stress responses. In Z. capensis, females do nest building and brooding while males defend territories by singing (Miller and Miller 1968) during the nesting phase. During the parental phase, both sexes provide parental care by feeding nestlings and fledglings (Miller and Miller 1968). In this study, we found no sex difference in either total or free maximal hormone levels or CBG capacity during both stages of breeding. Although this may be due to the sample size, our data support the parental care hypothesis even though the cost of nest abandonment in Z. capensis is presumably much lower than in Arctic birds due to more opportunities to renest. Further studies will be needed to examine relationships between time investment by both sexes and the sex differences in corticosterone secretion during nesting and parental phases in the Zonotrichia species.

We did not find any sex difference in CBG capacities, which we did not expect. In many temperate zone species, CBG capacities differ between sexes. Male pied flycatchers (F. hypoleuca), for example, had significantly higher CBG levels at the beginning of the breeding season; however, there was no difference during nesting (Silverin 1986). Higher CBG in males may be due to high testosterone levels in males during such times. In addition, testosterone implants elevated both corticosterone and CBG capacities in dark-eyed juncos (Junco hyemalis; Klukowski et al. 1997). Similarly, the testosterone-treated castrated males had significantly higher CBG levels than castrates without any treatment in the same species (Deviche et al. 2001). Both studies suggest that testosterone upregulates CBG capacities. This may be especially important for avian species because they lack sex steroid binding globulin in the blood (Deviche et al. 2001; Breuner and Orchinik 2002). Here, high CBG may be needed to protect tissues from high circulating levels of testosterone during breeding season. However, this is apparently not the case for $Z$. capensis. The effect of sex on CBG levels had a strong trend $(P=0.068)$; however, the observable difference was only during the early breeding stage where the difference in testosterone levels between sexes appears to be smaller. Similarly, there was no sex difference in CBG levels during middle breeding even though males had significantly higher testosterone levels than females. Moreover, there was no significant correlation between testosterone and CBG levels in males, which would be expected if testosterone upregulates CBG in this species. Rather, CBG capacity appears to follow the changes in corticosterone levels in Z. capensis. Further studies are needed to investigate the direct relationship between testosterone, corticosterone, and CBG in tropical passerines.

It is worth noting that progesterone also binds CBG with high affinity (Deviche et al. 2001) and may alter calculation of 
free corticosterone or affect CBG levels differently between the sexes. This may be especially important during middle breeding when progesterone levels reach their peak. However, progesterone levels range between 1 and $2 \mathrm{ng} / \mathrm{mL}$ during the middle breeding stage in this population (Moore et al. 2005). In addition, this possibility was explored in starlings, indicating progesterone does not play a significant role in modulating free corticosterone levels (Love et al. 2004).

In addition to environment and life-history strategies, social roles such as the amount of parental care may have a profound effect on the reactivity of the HPA axis. All lead to modulation of how tightly HPA axis and the bioavailability of glucocorticoids are regulated, according to the breeding environment and life-history strategies. This may be adaptive, since it can minimize the cost of hyper- and hyposensitivity to stress while maximizing the fitness. Zonotrichia provide a good model system for sister species comparisons as different species and subspecies inhabit a variety of latitudes and exhibit very different natural histories.

\section{Acknowledgments}

We thank the Fundación Terra and Termas de Papallacta for their permission to conduct this work on their property. We thank M. Swett and G. Salze for their editorial comments and L. Erckmann for assisting in steroid assays. This research was supported by National Science Foundation (NSF) grants IBN9905679 to J.C.W. and IBN-0202676 to C.W.B. and NSF Minority Postdoctoral Fellowship DBI-9904144 to I.T.M.

\section{Literature Cited}

Astheimer L.B., W.A. Buttemer, and J.C. Wingfield. 1994. Gender and seasonal differences in the adrenocortical response to ACTH challenge in an Arctic passerine, Zonotrichia leucophrys gambelii. Gen Comp Endocrinol 94:33-43.

Barsano C.P. and G. Baumann. 1989. Editorial: simple algebraic and graphic methods for the apportionment of hormone (and receptor) into bound and free fractions in binding equilibria; or how to calculate bound and free hormone? Endocrinology 124:1101-1106.

Bendix J. and M.D. Rafiqpoor. 2001. Studies on the thermal conditions of soils at the upper tree line in the paramo of Papallacta (eastern condillera of Ecuador). Erdkunde 55:257276.

Breuner C.W., S.E. Lynn, G.E. Julian, J.M. Cornelius, B.J. Heidinger, O.P. Love, P.S. Sprague, H. Wada, and B.A. Whitman. Forthcoming. Plasma binding globulins and the acute stress response. Horm Metab Res.

Breuner C.W. and M. Orchinik. 2001. Seasonal regulation of membrane and intracellular corticosteroid receptors in the house sparrow brain. J Neuroendocrinol 13:412-420.
2002. Beyond carrier proteins: plasma binding proteins as mediators of corticosteroid action in vertebrates. J Endocrinol 175:99-112.

Breuner C.W., M. Orchinik, T.P. Hahn, S.L. Meddle, I.T. Moore, N.T. Owen-Ashley, T.S. Sperry, and J.C. Wingfield. 2003. Differential mechanisms for plasticity of the stress response across latitudinal gradients. Am J Physiol 285:594-600.

Chapman F.M. 1940. The post-glacial history of Zonotrichia capensis. Bull Am Mus Nat Hist 77:381-438.

Deviche P., C. Breuner, and M. Orchinik. 2001. Testosterone, corticosterone, and photoperiod interact to regulate plasma levels of binding globulin and free steroid hormone in darkeyed juncos, Junco hyemalis. Gen Comp Endocrinol 122:6777.

Ekins R. 1990. Measurement of free hormones in blood. Endocr Rev 11:5-46.

Goymann W., I.T. Moore, A. Scheuerlein, K. Hirschenhauser, A. Grafen, and J.C. Wingfield. 2004. Testosterone in tropical birds: effects of environmental and social factors. Am Nat 164:327-333.

Gwinner E. and J.P. Dittami. 1990. Endogenous reproductive rhythms in a tropical bird. Science 249:906-908.

Hau M., M. Wikelski, K.K. Soma, and J.C. Wingfield. 2000. Testosterone and year-round territorial aggression in a tropical bird. Gen Comp Endocrinol 117:20-33.

Holberton R.L. and J.C. Wingfield. 2003. Modulating the corticosterone stress response: a mechanism for balancing individual risk and reproductive success in Arctic-breeding sparrows? Auk 120:1140-1150.

Kalma D.L. 1970. Some aspects of the breeding ecology and annual cycle of three populations of the rufous-collared sparrow (Zonotrichia capensis) in western Panama. $\mathrm{PhD}$ diss. Yale University, New Haven, CT.

King J.R. 1973. The annual cycle of the rufous-collared sparrow (Zonotrichia capensis) in three biotopes in north-western Argentina. J Zool (Lond) 170:163-188.

- 1974. Notes on geographical variation and the annual cycle in Patagonian population of the rufous-collared sparrow Zonotrichia capensis. Ibis 116:74-83.

Klukowski L.A., J.M. Cawthorn, E. Ketterson, and V. Nolan Jr. 1997. Effects of experimentally elevated testosterone on plasma corticosterone and corticosteroid-binding globulin in dark-eyed junco (Junco hyemalis). Gen Comp Endocrinol 108:141-151.

Love O.P., C.W. Breuner, F. Vezina, and T.D. Williams. 2004. Mediation of a corticosterone-induced reproductive conflict. Horm Behav 46:59-65.

Lynn S.E., C.W. Breuner, and J.C. Wingfield. 2003a. Short-term fasting affects locomotor activity, corticosterone, and corticosterone binding globulin in a migratory songbird. Horm Behav 43:150-157.

Lynn S.E., K.E. Hunt, and J.C. Wingfield. 2003b. Ecological factors affecting the adrenocortical response to stress in 
chestnut-collared and McCown's longspurs (Calcarius ornatus, Calcarius mccownii). Physiol Biochem Zool 76:566576.

Miller A.H. 1961. Molt cycles in equatorial Andean sparrows. Condor 63:143-161.

Miller A.H. and V.D. Miller. 1968. The behavioral ecology and breeding biology of the Andean sparrow, Zonotrichia capensis. Caldasia 10:83-154.

Moore I.T., F. Bonier, and J.C. Wingfield. 2005. Reproductive asynchrony and population divergence between two tropical bird populations. Behav Ecol 16:755-762.

Moore I.T., N. Perfito, H. Wada, T.S. Sperry, and J.C. Wingfield. 2002. Latitudinal variation in plasma testosterone levels in birds of the genus Zonotrichia. Gen Comp Endocrinol 129: 13-19.

Moore I.T., H. Wada, N. Perfito, D.S. Busch, T.P. Hahn, and J.C. Wingfield. 2004a. Territoriality and testosterone in an equatorial population of rufous-collared sparrows, Zonotrichia capensis. Anim Behav 67:411-420.

Moore I.T., J.C. Wingfield, and E.A. Brenowitz. 2004b. Plasticity of the avian song control system in response to localized environmental cues in an equatorial songbird. J Neurol Sci 24:10182-10185.

Morton M.L. 2002. Mountain White-Crowned Sparrow: Migration and Reproduction at High Altitude. Cooper Ornithological Society, Camarillo, CA.

O'Reilly K.M. and J.C. Wingfield. 2001. Ecological factors underlying the adrenocortical response to capture stress in Arctic-breeding shorebirds. Gen Comp Endocrinol 124:1-11.

Pemberton P.A., P.E. Stein, M.B. Pepys, J.M. Potter, and R.W. Carrell. 1988. Hormone binding globulins undergo serpin conformational change in inflammation. Nature 336:257258.

Romero L.M. 2002. Seasonal changes in plasma glucocorticoid concentrations in free-living vertebrates. Gen Comp Endocrinol 128:1-24.

Romero L.M., M. Ramenofsky, and J.C. Wingfield. 1997. Season and migration alters the corticosterone response to capture and handling in an arctic migrant, the white-crowned sparrow (Zonotrichia leucophrys gambelii). Comp Biochem Physiol C 166:171-177.

Romero L.M., K.K. Soma, and J.C. Wingfield. 1998a. Changes in pituitary and adrenal sensitivities allow the snow bunting (Plectrophenax nivalis), an Arctic-breeding songbird, to modulate corticosterone release seasonally. J Comp Physiol B 168: 353-358.

- 1998b. Hypothalamic-pituitary-adrenal axis changes allow seasonal modulation of corticosterone in a bird. Am J Physiol 274:1338-1344.

Romero L.M. and J.C. Wingfield. 1998. Seasonal changes in adrenal sensitivity alter corticosterone levels in Gambel's white-crowned sparrows (Zonotrichia leucophrys gambelii). Comp Biochem Physiol C 119:31-36.
1999. Alterations in hypothalamic-pituitary-adrenal function associated with captivity in Gambel's whitecrowned sparrows (Zonotrichia leucophrys gambelii). Comp Biochem Physiol B 122:13-20.

Sapolsky R.M. 1992. Neuroendocrinology of the stress-response. Pp. 287-324 in J.B. Becker, S.M. Breedlove, and D. Crews, eds. Behavioral Endocrinology. MIT Press, Cambridge, MA.

Sapolsky R.M., L.M. Romero, and A.U. Munch. 2000. How do glucocorticoids influence stress response? integrating permissive, suppressive, stimulatory, and preparative actions. Endocr Rev 21:55-89.

Silverin B. 1986. Corticosterone-binding proteins and behavioral effects of high plasma levels of hormones in a freeliving population of pied flycatchers, Ficedula hypoleuca. Gen Comp Endocrinol 64:67-74.

Wikelski M., M. Hau, and J.C. Wingfield. 1999. Social instability increases plasma testosterone in a year-round territorial Neotropical bird. Proc R Soc Lond B Biol Sci 266:551-556.

Wingfield J.C. 1994. Modulation of the adrenocortical response to stress in birds. Pp. 520-528 in K.G. Davey, R.E. Peter, and S.S. Tobe, eds. Perspectives in Comparative Endocrinology. National Research Council of Canada, Ottawa.

Wingfield J.C., and D.S. Farner. 1993. The endocrinology of wild species. Pp. 163-327 in D.S. Farner, J.R. King, and K.C. Parkes, eds. Avian Biology. Vol. 9. Academic Press, New York. Wingfield J.C., R.E. Hegner, and D. Lewis. 1991. Circulating levels of luteinizing hormone and steroid hormones in relation to social status in the cooperatively breeding whitebrowed sparrow weaver, Plocepasser mahili. J Zool (Lond) 225:43-58.

Wingfield J.C. and A.S. Kitaysky. 2002. Endocrine responses to unpredictable environmental events: stress or anti-stress hormones? Integr Comp Biol 42:600-609.

Wingfield J.C., K.M. O’Reilly, and L.B. Astheimer. 1995. Modulation of the adrenocortical response to acute stress in Arctic birds: a possible ecological basis. Am Zool 35:285-294.

Wingfield J.C. and L.M. Romero. 2000. Adrenocortical responses to stress and their modulation in free-living vertebrates. Pp. 211-236 in B.S. McEwen, ed. Handbook of Physiology. Oxford University Press, Oxford.

Wingfield J.C. and R.M. Sapolsky. 2003. Reproduction and resistance to stress: when and how. J Neuroendocrinol 15:711724.

Wingfield J.C., J.P. Smith, and D.S. Farner. 1982. Endocrine responses of white-crowned sparrows to environmental stress. Condor 84:399-409.

Wingfield J.C., C.M. Vleck, and M.C. Moore. 1992. Seasonal changes of the adrenocortical response to stress in birds of the Sonoran Desert. J Exp Zool 264:419-428.

Wolf L.L. 1969. Breeding and molting periods in a Costa Rican population of the Andean sparrow. Condor 71:212-219. 